\title{
Control and prevention of tuberculosis: a code of practice
}

When the Joint Tuberculosis Council of the British Tuberculosis Association-as it was then calledissued a report on the control of tuberculosis 20 years ago, an editorial that appeared in The Medical Officer commented that "this report commends itself as being honest and forthright ... It merits careful study, and we believe that it will be consulted as a standard dissertation on tuberculosis practice for some time to come. Those responsible for its inception and execution are to be congratulated."' I believe that the same may be said of the recent report on the control and prevention of tuberculosis issued by the Joint Tuberculosis Committee of the British Thoracic Society, ${ }^{2}$ and that this code of practice is equally applicable throughout Europe, North America, and other favoured parts of the world. It is authoritative and up to date and is based on sound scientific principles-Britain has been particularly fortunate in recent years in the quality of the epidemiological and control studies carried out by the British Thoracic Association (now Society), ${ }^{3-5}$ the Medical Research Council, ${ }^{7}$ and the Working Party on Tuberculosis in Scotland. ${ }^{8}$ The justification for issuing a code of practice at this time is that many of the physicians who had extensive experience of tuberculosis control have recently retired, and that the tuberculosis service has been actively dismantled in many areas. Not everyone will agree with everything that appears in the code of practice but it is a distillation of the combined wisdom of clinicians, microbiologists, epidemiologists, and community physicians and it offers excellent guidelines to all health workers.

\section{Infectiousness and segregation of patients with tuberculosis}

The report gives the following very specific advice: "For practical purposes patients with pulmonary tuberculosis in whose sputum tubercle bacilli were seen on direct examination should be regarded as non-infectious after two weeks of chemotherapy including rifampicin [the italics are mine] but may not remain so unless regular and adequate chemotherapy is continued thereafter." Several minor caveats follow and these will be discussed below. The opportunity to be more specific and to recommend such a short period of segregation arises from microbiological evidence on the activity of rifampicin on mycobacteria and several studies of disease in contacts. Furthermore, patients are now mainly treated in wards in general hospitals, tuberculosis sanatoria having virtually disappeared in developed countries.

The number of live tubercle bacilli in sputum (as shown by growth in culture) falls by $99 \%$ after the first two weeks' chemotherapy. ${ }^{9}$ It is true that Jenkinson et $\mathrm{l}^{10}$ found that sputum specimens from 15 patients who had received six weeks of antituberculosis treatment produced active disease when injected into guinea pigs (there were positive tissue smears in half and positive tissue cultures in three quarters of these), but the outcome of transmitting tubercle bacilli to guinea pigs by intraperitoneal injection is likely to differ considerably from the transmission of tubercle bacilli from infectious patients to contacts. The frequency of cough diminishes rapidly after the start of effective chemotherapy and Loudon and Spohn showed that children acquired less infection from patients who coughed less."

The evidence from patients stems from the classic Madras study, which showed that treatment at home, provided that the drugs were taken faithfully, caused no more risk for those living in the patient's home than existed for contacts of patients treated in a sanatorium at any time during the year of treatment or in the following five years. ${ }^{12}$ Similar results have subsequently been reported by Gunnels et al $^{13}$ and Riley and Moodie. ${ }^{14}$ The report, however, rightly emphasises that the period of segregation may need to be lengthened for those whose close contacts include infants or young children or immunosuppressed patients and for individuals who may be harbouring drug resistant mycobacteria and those, such as itinerants or alcoholics, whose compliance is very unsatisfactory.

Stanford ${ }^{15}$ on the other hand believes that all patients should be isolated for two weeks even if bacilli have not been seen in sputum to guard against the sporadic appearance of large numbers of bacilli released when small foci of disease break down into a bronchiole. Rifampicin is, however, particularly effective against tubercle bacilli undergoing spurts of growth. The report recommends that patients in whom three or more sputum smears give negative results on direct examination and those who have non-pulmonary tuberculosis even although tubercle 
bacilli have been cultured from specimens of the lesion should be regarded as non-infectious. Few would disagree with this advice.

Interestingly, despite the length of time which has elapsed since attitudes to the management of tuberculosis began to change, $78 \%$ of patients in England and Wales in 1978-9'6 and 69\% in Scotland in $1981^{8}$ were still admitted to hospital, the most common reason given being investigation and diagnosis. The figure is higher in some other countries.

The report recommends accommodating the patient in a well ventilated single room or in a ward specifically set aside for patients with infectious tuberculosis. It maintains that, in general, barrier nursing; the wearing of gowns and masks during nursing procedures; and special care of crockery, books, and linen (fomites) are all unnecessary, though masking during nursing procedures may be considered advisable for highly infectious or irresponsible patients. Ayliffe, ${ }^{17}$ however, while maintaining that it is difficult to obtain good evidence on the necessity or otherwise of some of these procedures and that distinction between ritual and rational methods is not always clear, counsels that we should err on the side of safety in a disease such as tuberculosis, and advises retention of the procedures which the report states are unnecessary. He maintains that washing hands after handling a patient is the most important component of the barrier nursing technique and its abandonment will be misleading, but it is hardly likely that the authors of the report envisaged hand washing as peculiar to barrier nursing. The discrepancy of view might be attributable to the slightly different slant of the clinician and microbiologist, but the Joint Tuberculosis Council has microbiologists as members.

\section{Protection against tuberculosis in NHS employees}

The duty to protect staff from infection by tuberculosis is self-evident but the correct policy is very difficult to formulate. If a policy is too elaborate, it may be impossible to enforce it, so that it may well be less effective than a simpler one which can be readily imposed and regulated. Although it is normally easy to define those who are at high risk and those who, if they develop the disease, may put susceptibles at risk, there is frequently difficulty in deciding who is at only normal risk. (The word "normal" appeared originally in the report as "minimal" in error.)

The report defines those at normal risk as persons in regular contact with patients, laboratory workers, and others who handle material that does not contain tubercle bacilli. Perhaps it should have warned specifically that all persons handling sputum or tis- sue from lungs may be at risk from unsuspected material. Those at normal risk are recommended to undergo as part of a pre-employment examination a radiograph of the chest and a tuberculin test (Heaf or Mantoux), and BCG is advised for non-reactors to tuberculin, postvaccination tests not normally being required. Those who refuse BCG vaccination should be specially recorded so that they are not employed in jobs where there is high risk, and they should be tuberculin tested at six monthly intervals.

Pre-employment examination of those who are in the high risk group-in regular contact with patients known to have tuberculosis or laboratory workers who handle potentially tuberculous material (not forgetting necropsy attendants, who may be exposed to aerosols of tubercle bacilli from the not inconsiderable number of patients who die from unsuspected tuberculosis)-should include a chest radiograph and tuberculin test with appropriate protection by BCG vaccination for non-reactors. Evidence of satisfactory vaccination should be sought in such people. Furthermore, annual radiographic examination should be offered to them.

The report recommends that all staff working in obstetric or children's departments should be required to have annual chest $x$ ray examinations. There have been several instances recently of children being infected with tuberculosis by hospital staff and it is extremely difficult to keep a record of staff who rotate through such departments, often for quite short periods. Staff are increasingly conscious of the risks of radiation (although the risk from a single large film examination is negligible). Such staff should nevertheless be required to undergo annual $x$ ray examination.

Attention has been drawn by Jachuck and Bound ${ }^{18}$ to the fact that the recommendation of the report that tuberculosis patients should more and more be cared for at home focuses attention on a potential gap in the protection of persons who care for them at home and who may have been infected before the diagnosis was made and chemotherapy commenced. They recommend protection programmes for primary care teams similar to those recommended for hospital employees.

\section{Control of tuberculosis among school teachers and local authority staff}

The report draws attention to a regulation issued by the Chief Medical Officer in 1982 that a chest radiograph is no longer a mandatory part of the medical examination of school teachers on entry to the profession in England and Wales but that it may be advised at the discretion of the examining doctor, ${ }^{19}$ and proceeds to indicate that local authority staff 
and others whose duties entail regular and close work with children are currently advised to have a pre-employment chest $x$ ray examination. These recommendations may well be considered to be somewhat paradoxical, particularly as they follow immediately after an expression of the necessity for protection of children in obstetric and children's departments against infection by staff suffering from unsuspected tuberculosis. In Scotland, on the other hand, a pre-employment chest radiograph for school teachers and nursery nurses is mandatory and the same rule applies to social work staff. ${ }^{20}$

\section{Tuberculosis in schools}

The discovery of tuberculosis among schoolchildren or members of school staff, who may be the source of infection, is a cause for alarm among parents and education authorities. Nor should it be forgotten that schoolchildren may be infected by people other than a teacher, as shown by the outbreak of tuberculosis amongst 3764 contacts of a swimming bath attendant whose sputum was positive, $108(2.9 \%)$ of whom were found to have been infected. ${ }^{21}$

The commitee recommends that investigation of contacts is required only if the index patient suffers from pulmonary tuberculosis. If the source is sputum positive all children in the year and members of staff who have not had BCG vaccination should be tuberculin tested and the positive reactors should be referred for $x$ ray examination. The negative reactors should be retested with tuberculin six weeks after contact has been broken to ensure that any tuberculin converters may be identified. Those who have had BCG should also have chest radiographs, ideally three months after diagnosis of the index case.

\section{Contact with infectious tuberculosis in hospital}

The report makes only very brief reference to the action which should be taken in respect of examination of contacts when a patient is found to be suffering from infectious tuberculosis in a general ward. This is, however, a matter which often causes much anxiety, among the nursing hierarchy in particular.

There is often an insistent demand on the part of certain members of staff to have a chest radiograph as soon as a patient under their care is found to have tuberculosis. This is irrational because of the lapse of time which must occur between infection and disease in tuberculosis. In my view the following procedure should be adopted. The correct time for $x$ ray examination is three to six months later. It is best if, in consultation between a specialist in respiratory medicine, the physician in charge of the patient, the microbiologist, and the ward sister, the degree of risk is determined and a list of contacts (including ward cleaners) compiled. The contacts should then be dealt with in the manner set out below.

It should be explained to staff that the likelihood of developing disease is extremely small, especially if they have been protected by BCG vaccination. Those hospitals which ensure maximum protection through the meticulous efforts of an occupational health service or nurse are able to convey this assurance to staff with the maximum conviction. The importance of such an organisation is illustrated by the experience in a Newcastle hospital, where out of 2501 staff who had pre-employment assessments $587(24 \%)$ individuals had no evidence of having had BCG, and were not aware of having had a tuberculin test. Fifty $(8.5 \%)$ of these individuals were found to have a grade 4 Heaf reaction. ${ }^{18}$

\section{Examination of contacts}

The report emphasises that the examination of contacts in Britain is a necessary and valuable procedure - in Scotland, for example, $11 \%$ of all notifications in 1981 were a result of contact tracing. ${ }^{8}$

A detailed account of the procedures recommended is given in the report: suffice it for the principles to be discussed briefly here. Recent studies have confirmed that the risk to contacts is much higher if the index patient is sputum smear positive and if the contact shares accommodation with him or her. ${ }^{3}$ Non-household and casual contacts run a very low risk $(0.3 \%)$, whereas $9 \%$ of Asian and $12 \%$ of non-Asian contacts of patients with sputum smear positive disease develop active disease. Maximum efforts must therefore be directed towards examination of household contacts of patients with sputum smear positive disease. Even in centres which have made strenuous efforts in contact examination some $10 \%$ of contacts fail to attend for initial examination, and with the phasing out of the specialist tuberculosis health visitor in many areas this figure is likely to increase.

Most disease is discovered at the time of initial examination. The report recommends follow up examination for $(a)$ those with grade 3 or 4 reactions (Heaf) who are not given chemoprophylaxis, provided that they have not had BCG vaccination or previous tuberculosis, for two years; $(b)$ household contacts of Asian index patients with pulmonary disease, who should be followed up for two years since in $14 \%$ of cases pulmonary disease is found by the end of the second year of follow up. The British Thoracic Association contact study, ${ }^{3}$ however, suggests that in non-Asian communities contacts of 
sputum smear positive patients should be followed up for one year.

The report does not specify the frequency of $x$ ray examination. Unpublished data from Edinburgh suggest that $75 \%$ of contacts found to have disease other than at the initial examination are discovered at three months. Perhaps the ideal would be $x$ ray examination at three and 12 months, and, in all Asians and in contacts of non-Asian patients who are sputum smear positive, at 24 months also.

The adequacy of contact examination depends not only on the compliance of contacts but also on the standard of notification by doctors. This is not always adequate and has been the subject of discussion recently. ${ }^{22}$ It is important to notify tuberculosis discovered at necropsy, and the practice carried out by some microbiological laboratories of forwarding copies of reports of isolations of mycobacteria to the "proper officer" (normally the medical officer for environmental health) is to be recommended.

\section{BCG vaccination}

The report recommends the continuation of the policy of BCG vaccination offered routinely in schools to children aged 10-14 years until the risk of infection is low everywhere in Britain. The justification for continuing vaccination throughout the country even although tuberculosis is now very rarely encountered in many areas is the mobility of the population, many young people seeking work in urban areas where tuberculosis is more prevalent. It has been shown that, whereas in 1950-52 1495 notified cases were estimated to have been prevented by the scheme and only 67 vaccinations were required to prevent one notification, the estimated figures for 1978 were 44 and 2300 respectively per 100000 schoolchildren in England and Wales. ${ }^{5}$ If the prevention of even a small number of cases is regarded as of overriding importance then the schools scheme should be continued almost indefinitely.

Emphasis is rightly placed on the importance of vaccination technique, which has been set out in detail by the Public Health Laboratory Service Communicable Diseases Surveillance Centre. ${ }^{23}$ The technique of a truly intradermal injection by needle and syringe is one that needs training and practice. Vaccination programmes are now often left in the hands of inexperienced personnel and, although poor technique may result only in minor discomfort and unsightly blemishes, it occasionally results in serious problems, such as subcutaneous abscesses.

As has been stated, BCG vaccination is also applicable to tuberculin negative people in the following categories: children and the newborn from families where there is a high incidence of tuberculosis in their ethnic group, health service workers and others exposed to infection at work, household contacts of infectious patients, and students (medical, dental, nursing, professions allied to medicine, and those in teacher training colleges). One aspect which will assume greater importance in the future is the protection of staff by BCG vaccination, because the schools BCG programme is no longer complete in England and $\mathrm{Wales}^{24}$ and an administrative decision to abandon it altogether might well be taken within a few years, despite the cautionary words of the report.

\section{Screening of immigrants}

The report rightly emphasises the special problems which the disease presents in immigrant communities. A survey of England and Wales in 1978-9 showed an overall annual notification rate of 18.3 per 100000 but for the ethnic groups from the Indian subcontinent it was 382 . There was considerable regional variation and in one region the annual notification rate was 1132 per $100000 .^{7}$ The problem of tuberculosis in immigrants is not, or course, confined to Britain.

The control programme falls naturally into two parts-firstly, the detection of active tuberculosis among new immigrants and, secondly, the identification of those for whom chemoprophylaxis or BCG vaccination may be appropriate. Special attention needs to be given to those from the Indian subcontinent and the Vietnamese boat people, who have the highest tuberculosis rates.

It is important that immigrants are identified at the point of arrival in the country, and that the address of the intended place of settlement is obtained and notified to the appropriate medical officer of environmental health. Immigrant populations are mobile and prompt action by all concerned, particularly local medical officers and family doctors, is essential if a substantial proportion of the population is not to be lost from the screening programme. $\mathrm{McNicol}^{25}$ reminds us that immigrant communities contain in their number susceptible individuals with negative responses to tuberculin tests who are exposed to particular risk by close association with infectious patients, often in overcrowded conditions.

The report suggests that starting the programme in the house is helpful in gaining the confidence of immigrants and contacting as many of them as possible. The Heaf test is given and read in the house and appropriate arrangements are then made for chest $x$ ray examination and assessment or BCG vaccination. Chemoprophylaxis is recommended for 
Asian children under the age of 16 who have a positive reaction (Heaf 2-4) without evidence of previous vaccination, and it is probably justified up to the age of 40. Poor compliance in taking isoniazid for six to 12 months is a recognised problem and studies to assess the efficacy of shorter regimens containing rifampicin are in hand.

Although the value of chemoprophylaxis has not been established, the need for BCG vaccination of children from the Indian subcontinent is clear. The incidence of tuberculosis in those children is $\mathbf{5 0}$ times that of white children if they were born abroad and 20 times greater if they were born in Britain. ${ }^{6}$ BCG vaccination should therefore be given at birth to those born in Britain and as soon as possible after arrival in the case of those born abroad.

The Joint Tuberculosis Committee and the British Thoracic Society are to be congratulated on this excellent report, which is clear, sensible, and authoritative. It is issued most opportunely at a time when, with the decline of tuberculosis, expertise that was previously widespread is no longer so readily available. Health workers of all kinds are faced from time to time with the problems which are dealt with here and, if they have not already done so, the authorities should ensure that the report is widely disseminated.

NW HORNE

10 Corrennie Gardens Edinburgh EH10 6DG

\section{References}

' Anonymous. The Medical Officer 1962;107:319.

2 Joint Tuberculosis Committee of the British Thoracic Society. Control and prevention of tuberculosis: a code of practice. $\mathrm{Br}$ Med J 1983;287:1118-21.

${ }^{3}$ British Thoracic Association. A study of a standardized contact procedure in tuberculosis. Tubercle 1978;59:245-59.

4 Joint Tuberculosis Committee. Tuberculosis among immigrants in Britain. Br Med J 1978; i:1038-40.

${ }^{5}$ Research Committee of the British Thoracic Association. Effectiveness of BCG vaccination in Great Britain. Br J Dis Chest 1980;74:215-27.

- Medical Research Council Tuberculosis and Chest Diseases Unit. Tuberculosis in a national survey of notifications in England and Wales, 1978-1979. Arch Dis Child 1982;57:734-41.

${ }^{7}$ Medical Research Council Tuberculosis and Chest Disease Unit. The geographical distribution of tuberculosis notifications in a national survey of England and Wales (1978-79). Tubercle 1982;63:75-88.
* Working Party on Tuberculosis. Report number nine and ten. Scottish pulmonary tuberculosis survey (SMR 14). December 1983. Information Services Division. Edinburgh: 1982.

9 Jindan A, Aber VR, Edwards A, Mitchison DA. The early bactericidal activity of drugs in patients with pulmonary tuberculosis. Am Rev Respir Dis 1980;121:939-49.

10 Jenkinson SG, George RB, Light RW, Grafton W, West $B C$. Serial observations of infectivity of mycobacterium tuberculosis in the sputum of patients receiving anti-tuberculosis therapy. Am Rev Respir Dis 1979;119, suppl 1:403.

" Loudon RG, Spohn SK. Cough frequency and infectivity in patients with pulmonary tuberculosis. Am Rev Respir Dis 1969;99:109-11.

12 Kamat RS, Dawson JJY, Devadatta S, et al. A controlled study of the influence of the segregation of tuberculous patients for one year on the attack rate of tuberculosis in a five year period in close family contacts in South India. Bull World Hlth Org 1966;34:517-32.

${ }^{13}$ Gunnells JJ, Bates JH, Swindoll $\mathrm{H}$. Infectivity of sputum-positive tuberculous patients on chemotherapy. Am Rev Respir Dis 1974;109:323-30.

14 Riley RL, Moodie AS. Infectivity of patients with pulmonary tuberculosis in inner city houses. Am Rev Respir Dis 1974;110:810-2.

is Stanford JL. Protection of hospital staff from tuberculosis. J Hosp Inf 1980; 1:183-6.

${ }^{16}$ Byfield SP, Citron KM, Darbyshire J, Fox W, Nunn AJ. Treatment of pulmonary tuberculosis in England and Wales. Thorax 1982;37:239.

17 Ayliffe GAJ. Control and prevention of tuberculosis. $\mathrm{Br}$ Med J 1983;287:1800.

18 Jachuck SJ, Bound CL. Control and prevention of tuberculosis. Br Med J 1983;287:1722-3.

${ }^{19}$ Chief Medical Officer. Education Act 1980; education (teachers) regulations 1982. London: Department of Education and Science, 1982.

${ }^{20}$ Scottish Education Department. Routine chest $x$-rays of teachers and social work staff. Edinburgh: Scottish Educational Department, 1983. (Circular letter DSW/1983.)

${ }^{21}$ Rao VR, Joanes RF, Kilbane P, Galbraith NS. Outbreak of tuberculosis after minimal exposure to infection. $\mathrm{Br}$ Med J 1980;3:187-9.

22 Joint Tuberculosis Committee of the British Thoracic Association. Notification of tuberculosis: code of practice for England and Wales. Br Med J 1982; 284:1454-6.

${ }^{23}$ Public Health Laboratory Service Communicable Disease Surveillance Centre. BCG Vaccination. Br Med J 1983;286:876-7.

${ }^{24}$ Miller CL, Morris J, Pollock TM. PHLS inquiry into current BCG vaccination policy. $\mathrm{Br}$ Med J 1984;288: 564 .

${ }^{25} \mathrm{McNicol} M$. Trends in the epidemiology of tuberculosis - a physician's view. J Clin Pathol 1983;36:1087-90. 